\title{
Determinants of Economic Growth: Evidence from Somalia
}

\author{
Ali Yassin Sheikh Ali ${ }^{1}$, Mohamed Saney Dalmar ${ }^{2} \&$ Ali Abdulkadir Ali ${ }^{3}$ \\ ${ }^{1}$ Faculty of Economics, SIMAD University, Mogadishu, Somalia \\ ${ }^{2}$ School of Graduate Studies, SIMAD University, Mogadishu, Somalia \\ ${ }^{3}$ Faculty of Humanities, University of Somalia, Mogadishu, Somalia \\ Correspondence: Ali Yassin, Faculty of Economics, SIMAD University, Mogadishu, ON., Jidka Warshadaha \\ 2526, Muqdisho, Somalia. Tel: 252-61-222-5577. E-mail: profali@ simad.edu.so
}

Received: Apri 9, 2017

doi:10.5539/ijef.v9n6p200
Accepted: May 22, 2017

Online Published: May 25, 2017

\begin{abstract}
Somalia has suffered enormous instability and civil war in the last three decades, which have impacted the population as well as the economy of the country. Although Somalia is the one of the most impoverished and corrupt nations in the world, it has registered small growth in recent years. The people of Somalia are entrepreneurial by nature and have established business firms both outside and inside the country. This paper aims to investigate empirically the causal relationships between economic growth and variables such as exports (X), foreign aid (FA), government expenditure (GE), gross capital formation (GCF), and foreign direct investment (FDI). The unit root of the data was tested for all variables, and the variables were non-stationary in the level model but stationary in the first-difference model. The null hypothesis of no co-integration was rejected, and the tests revealed a causal relationship among the variables in the study. Four of the six explanatory variables were not statistically significant. Only the variables of GCF and FDI were statistically significant for economic growth.
\end{abstract}

Keywords: economic growth, GDP, gross capital formation, foreign direct investment, Somalia

\section{Introduction}

The determinants of economic growth are increasingly attracting attention from researchers (Artelaris et al., 2007), and many macroeconomists authors have formulated ideas for growth-generating mechanisms, which were previously omitted at an intuitive level or were the subject of hand-waving (Romer, 1986; Lucas, 1988). The economies of some countries in sub-Saharan Africa remain vulnerable to domestic and external shocks, and many of these countries are emerging from civil wars that have hindered or worsened their development including Somalia.

After the fall of the military regime in 1991, Somalia underwent a long, bloody conflict involving more than twenty years of civil war and anarchy that tore apart the country, weakened and nearly destroyed many legitimate institutions, and generated general economic malaise. Despite severe political and economic challenges, a great deal of progress and improvements have occurred since the establishment of the Transitional Federal Government and subsequent Federal Government of Somalia. In recent years, such as 2015, there have been slight improvements in the general economy, despite difficulties in revenue collection and generation, with steady economic growth and low inflation. An increase in the size of the telecommunication industry is estimated to have added slightly to real gross domestic product (GDP) growth in 2015, which was estimated as 3.7\% (Worldbank, 2016).

Based on World Bank data, the GDP of Somalia in 2015 was approximately US $\$ 5,925$ million, up from US $\$ 5,647$ million in 2014 and representing an increase of 5\% in nominal terms. In addition, the consumer price index declined from $1.3 \%$ in 2014 to $1 \%$ in 2015 due to lower commodity prices, including oil. Household consumption expenditures and remittances are estimated to constitute the greatest part of GDP. Imports were estimated to be 60\% of GDP, while exports were $14.5 \%$. This imbalance between imports and exports has led to a deficit that is usually financed by foreign aid from donor countries.

Table 1. National income and prices, 2013-2015

\begin{tabular}{|c|c|c|c|}
\hline & 2013 & 2014 & 2015 \\
\hline Nominal GDP in millions of US dollars & 5,352 & 5,647 & 5,925 \\
\hline Real GDP, annual percentage change & 2.8 & 3.6 & 3.7 \\
\hline Per capita GDP in US dollars & 402 & 413 & 423 \\
\hline Consumer Price Index (CPI), annual percentage change & 4.5 & 1.3 & 4 \\
\hline
\end{tabular}


The foreign exchange rate briefing reveals the differences and fluctuations of the exchange rates on the buying and selling bases recorded by the Central Bank of Somalia. The report only reflects the exchange rate of the Somali shilling (SOS) against the US dollar because the US dollar is the largest foreign currency in use in Somalia and nearly the entire economy is dollarized. In 2012, the Somali exchange rate to the US dollar was stable, with the exception of a depreciation of approximately $9 \%$ in January to March.

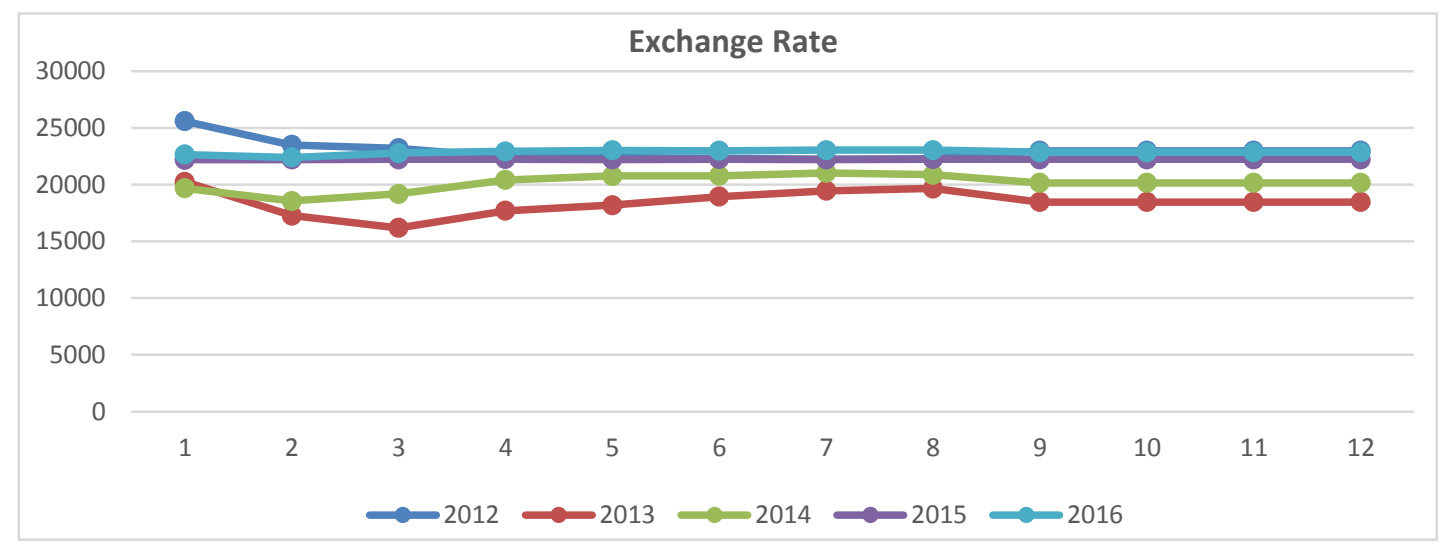

Figure 1. Exchange rate 2012-2016

In 2013, the first quarter was characterized by slight fluctuations in the exchange rate of SOS to US dollars, with a depreciation of approximately $20 \%$. By contrast, the exchange rate was nearly stable in the second quarter, and appreciation of approximately $4 \%$ was recorded from June to August, as shown in Figure 1. These data show that the exchange rate in Somalia is freely volatile because the Central Bank of Somalia has control of neither the exchange rate nor the supply of money. Currently, the only Somali currency in use is the 1000 shilling note.

The exchange rate was relatively stable in 2014, with a depreciation of approximately $6 \%$ in February from January and appreciation of $1.25 \%$ in July. In 2015, the exchange rate against the US dollar was also stable, with only $0.1 \%$ appreciation recorded in August. Finally, in 2016, the SOS exchange rate against the US dollar rose by approximately $10 \%$ from SOS 22,660 in January to an average rate of SOS 23,040. Somalia's exchange rate of SOS to the US dollar in from 2012 to 2015 was freely floating, and the circulation of counterfeit Somali currency in this period contributed to the fluctuations in the exchange rate.

The dependent variable used in the study is GDP, which reveals the rate of economic growth of a given country and is a proxy for investment development. According to our data, economic growth in Somalia has been slowly expanding from large cities, such as Mogadishu, Hargeysa, Bosaso, Kismanyo and Garowe, to regions, districts and villages that have been in recovery since the lessening of civil war. Capital formation, defined as that part of a country's current output and imports that is not consumed or exported during the accounting period but is set aside as an addition to its stock of capital goods, is one of the main explanatory factors in the economic growth of Somalia and is the first independent variable in our model (Haryana, 2014). Akinola and Omolade (2013) theorized that high savings and high levels of capital formation are prerequisites for long-term economic growth in any country. High levels of savings are necessary to finance high levels of capital formation, which will lead to increased productivity and, ultimately, long-term economic growth.

The second independent variable in our model is government final consumption expenditure, a key indicator provided by national accounts. Government final consumption expenditure is an important component of total GDP when derived by the expenditure approach. In addition, breaking down government final consumption expenditure into individual and collective components is important for estimating government actual consumption. Moreover, government final consumption expenditure on individual goods and services forms a part of household actual final consumption. Therefore, the analysis of various government consumption aggregates is a vital element of many economic and fiscal analyses.

Studies have suggested that the production of cumulative capital per worker increases with investment and the savings rate. In a competitive economy, real wages and real rental rates are determined by traditional marginal-productivity equations. Policies that affect the level of growth and investment efficiency are the determinants of long-run economic growth (Solow, 1956). Similarly, Tyler (1981) examined a sample of 55 developing countries and found that exports and investments are the main determinants of economic growth.

Basic economic studies and theories have investigated the causal relationship between exports and economic 
growth since this relationship was first proposed by David Ricardo in 1817. Because exports are one of the main determinants of economic growth, an increase in exports can contribute to an increase in economic growth. However, other mediating variables may also affect the causal relationship between exports and economic growth (Ricardo, N/A).

Foreign direct investment (FDI) has been found to positively affect the economic growth of a country but is dependent on other variables, such as the level of technological advancement of the host economy, economic stability, state investment policy and degree of openness. The implication is that FDI inflows can affect gross capital formation (GCF) because they are a source of financing, and hence capital formation is one of the prime determinants of economic growth (Dritsakis, Varelas, \& Adamopoulos, 2006). According to the economic literature, external debt (ED) is defined as all external obligations with a maturity of one year or longer that are outstanding at a particular point in time and are payable in terms of reserve currency or goods and services. This paper aims to study the determinants of economic growth in Somalia during the period 1970-2012.

\section{Literature Review}

Economic growth is an increase in the capacity of an economy to produce goods and services and can be measured in nominal or real terms, the latter of which is adjusted for inflation. Traditionally, aggregate economic growth is measured in terms of gross national product (GNP) or GDP, although alternative metrics are occasionally used. Economic growth has been the subject of extensive empirical research. The empirical study of the determinants of economic growth by Barro (1991) has become an important reference for studies in related fields. This section will briefly review factors that determine economic growth. The influences considered here include government spending, inflation, FDI, trade, and financial development.

The size of government expenditure and its effect on economic growth have received considerable attention. In a study of government spending and economic growth in Saudi Arabia, Ghali (1997) examined the inter-temporal interactions between the growth rate in per capita real GDP and government spending as a share of GDP using vector autoregressive (VAR) analysis, with particular attention on testing for the existence and direction of Granger causality among the variables. This empirical analysis found no consistent evidence that government spending increases Saudi Arabia's per capita output growth. Therefore, fiscal policy aimed at controlling the budget deficit in Saudi Arabia must consider shrinking the size of government and limiting its role in the economy.

By contrast, two studies by Cheng and Lai (1997) and Loizides and Vamvouka (2005) both suggested that government expenditure Granger-causes economic growth. Cheng and Lai (1997) examined the causality between government expenditure and economic growth along with money supply in a trivariate framework by applying VAR techniques to data for South Korea for the period 1954-94. Phillips-Perron (PP) unit root tests and Johansen's tests of co-integration revealed bidirectional causality between government expenditures and economic growth in South Korea, and money supply was also found to affect economic growth. Loizides and Vamvouka (2005) examined whether the relative size of government measured as the share of total expenditure in GNP Granger-causes the rate of economic growth or if the rate of economic growth Granger-causes the relative size of government. Loizides and Vamvouka employed a bivariate error correction model within a Granger-causality framework and added unemployment and inflation (separately) as explanatory variables to create a simple 'trivariate' analysis for each of these two variables. The combined analysis of the bivariate and trivariate tests offered a rich menu of possible causal patterns. Using data for Greece, the UK and Ireland, the analysis showed: i) government size Granger-causes economic growth in the short run in all countries in the sample and in the long run in Ireland and the UK; ii) economic growth Granger-causes an increase in the relative size of government in Greece and, when inflation is included, in the UK.

However, Loizides and Vamvouka (2005) also focused on the causal link between the size of the public sector and real per capita income within the bivariate and trivariate frameworks in their sample countries of the UK, Ireland and Greece. They drew three conclusions. First, public expenditure Granger-causes growth in the short run and long run in all sample countries. Second, both the bivariate and trivariate frameworks showed that an increase in output would cause growth in public expenditure in Greece. Third, their trivariate model indicated causality between national income and public spending in Greece and the UK. The different results of this study indicate that under certain circumstances, changes in government expenditure do not necessarily cause changes in economic growth when government spending delivers services inefficiently.

Financial development is the second factor that determines economic growth. Liang and Jian-Zhou (2006) employed a panel dataset for 29 Chinese provinces over the period of 1990-2001 and applied generalized method of moment (GMM) techniques to examine the impacts of financial development on China's growth performance. The empirical results showed that financial development significantly promotes economic growth in coastal regions but not inland 
regions; the weak finance-growth nexus in inland provinces may aggravate China's regional disparities. Ang and McKibbin (2007) included financial liberalization in their observations to evaluate whether financial development leads to economic growth or vice versa in the economy of Malaysia. Consistent with Liang and Jian-Zhou (2006), their analysis indicated that financial development leads to economic growth. A variety of approaches and empirical evidence demonstrated that financial sector development in Malaysia can be stimulated by financial liberalization if repressionist policies are removed. Moreover, financial depth and economic development tend to be positively related. Ang and McKibbin also view economic growth as generating higher financial depth in the long run.

In addition, Saad (2014) employed the VECM-based Granger-causality test to provide empirical evidence of a causal relationship between financial development and economic growth in Lebanon. Saad found that the credit market remains underdeveloped in Lebanon and that its contribution to economic growth is limited due to a lack of financial depth. Therefore, Saad focused on the banking sector to measure financial development, which revealed a positive relationship between financial development and economic growth in the short run accompanied by bidirectional Granger causality between these variables. However, this relationship was insignificant in the long run. Moreover, the results indicated that the efficiency of the banking sector has an important role in economic growth in Lebanon.

The third factor that determines economic growth is inflation, which has been the subject of numerous studies. Hussain and Malik (2011) examined the nexus between inflation and economic growth in the context of the economy in Pakistan. To examine the extent to which economic growth is related to inflation and vice versa, error correction models (ECMs) were employed. The results indicated that inflation deviates from its equilibrium value. For instance, the error correction term of -0.49 implied that $49 \%$ of the adjustments towards the short-run equilibrium relation for Pakistan occur within a year through changes in growth rates. On the other hand, 58\% (error correction term -0.58) of the deviation of the inflation from its short-run equilibrium level is corrected each year. Furthermore, the estimated threshold model suggested a 9\% threshold level (i.e., structural break point) of inflation above which inflation starts to reduce economic growth in Pakistan. Thus, Pakistan requires single-digit inflation for growth, and a growth rate that is too rapid may also accelerate inflation. Mallik and Chowdhury (2001) analyzed the relationship between inflation and GDP growth in four South Asian countries: Bangladesh, India, Pakistan and Sri Lanka. They employed co-integration models and ECMs with annual data retrieved from the IMF International Financial Statistics. They obtained two results: (i) inflation and economic growth are positively and statistically significantly related for all four countries; (ii) the sensitivity of growth to changes in inflation rates is smaller than that of inflation to changes in growth rates. These results have crucial policy implications; that is, although moderate inflation fosters economic growth, economic growth feeds back into inflation by stimulating the economy.

Faria and Carneiro (2001) claimed a divergent view from that of Mallik and Chowdhury (2001) in a study of the relationship between inflation and economic growth in Brazil, which had experienced severe inflation. Using a bivariate time-series model (VAR) with annual data for the period between 1980 and 1995, Faria and Carneiro argued that although there is a negative relationship between inflation and economic growth in the short run, in the long run, economic growth is not affected by inflation. This result supports the theory that hyperinflation is usually associated with economic depression and political and social upheaval and, consequently, contradicts the perspective that inflation affects economic growth in the long run.

The final determinants of economic growth examined are FDI and trade. Saqib, Masnoon, and Rafique (2013) provided contrasting evidence on the impact of FDI on the economy of the host country (Pakistan). The methodology to test the impact of these variables on Pakistan's economy was limited to the least-squares method, which revealed that Pakistan's economic performance is negatively affected by foreign investment, whereas domestic investment benefits its economy.

Similarly, Louzi and Abad (2011) investigated the impact of FDI on economic growth in Jordan and focused on the FDI-led growth hypothesis. The study was based on time-series data from 1990 to 2009. An integrated econometric framework and error correction mechanism were used to capture two-way linkages between variables of interest. The econometric result showed that FDI inflows do not exert an independent influence on economic growth. In addition, the impact of DIN and TP on the GDP growth rate was found to be positive. These results indicate that the ultimate objective of the Jordanian government to attract FDI for development requires an appropriate policy mix.

Makki and Somwaru (2004) analyzed the roles of FDI and trade in promoting economic performance across 66 developing countries and the interaction among FDI, trade and economic growth by adopting the seemingly unrelated regressions (SUR) method and instrumental variable (3-stage least squares) approach over the period of 1971-2001. They obtained four interesting results. First, the variables of FDI and trade have a strong positive relationship. Second, FDI stimulates domestic investment. Third, macroeconomic policies and institutional stability are preconditions for FDI-driven growth. Fourth, economic growth is facilitated by reductions in the inflation rate, tax burden, and 
government consumption.

\section{Methodology and Model Development}

\subsection{Data and Methodology}

This research utilizes annual time-series data from the World Bank database and International Monetary Fund for the sample period 1970-2012. Ordinary least-squares (OLS) regression was used to establish relationships between the independent variables (6 variables) and real GDP as the dependent variable to measure economic growth. An economic approach was employed to estimate the determinants of economic growth. The OLS technique was employed to obtain numerical estimates of the coefficients in the econometric equation based on its optimal properties: its computational procedure is fairly simple, and it possesses best linear unbiased estimator (BLUE) properties.

\subsection{Model Specification}

Mathematical specification involves the transformation of a proposed theory into mathematical form. In this study, the following mathematical outward appearance is proposed.

The functional relationship among FDI, ED, GCF, foreign aid, exports, government expenditure and the economic growth of Somalia is expressed as the following:

$$
G D P=F(F D I, E D, G C F, F A, G E, X)
$$

GDP is real gross domestic product, $\mathrm{F}$ is the function of economic growth, FDI is the stock of foreign direct investment, ED is external debt, FA is foreign aid, GE is government expenditure, GCF is gross capital formation, and $\mathrm{X}$ is exports. The equation can be further written in linear form as follows:

$$
Y=\beta 1+\beta 2 E D+\beta 3 F A+\beta 4 F D I+\beta 5 G C F+\beta 6 G E+\beta 6 X+\mu
$$

where $\mathrm{Y}$ is economic growth (dependent variable); $\beta 1$ is a constant; $\beta 2-\beta 6$ are slope coefficients that measure the marginal increment of economic growth; FDI, ED, GCF, FA, GE, and X are foreign direct investment, external debt, gross capital formation, foreign aid, government expenditure and exports, respectively (independent variables); and $\mu$ is the error term or residual.

\section{Results}

The previous section detailed the research methodology adopted to test the proposed theoretical model and answer the research objectives of the study. This section presents the findings of the data analysis and is presented in six subsections. The first subsection is the descriptive analysis of the main variables of the model; the second subsection presents the unit root test; the third subsection discusses the model test using regression analysis; the fourth and fifth sections discuss the normality test and validity measures of the data; and the sixth subsection discusses the hypotheses tested and model fitness findings.

\subsection{Descriptive Analysis of the Main Variables of the Model}

As shown in Figure 2, Somalia's exports of goods and services have suffered a continuous decline since the collapse of the military regime in 1990. During 1970-1976, there was a huge increase in exports of goods and services to beneficiary countries such as Saudi Arabia, Yemen and Oman. After 1977, the country faced different challenges, such as conflict. Between 1977 and 1991, there was a dramatic decrease in exports due to the collapse of the state and other issues such as clan fighting.

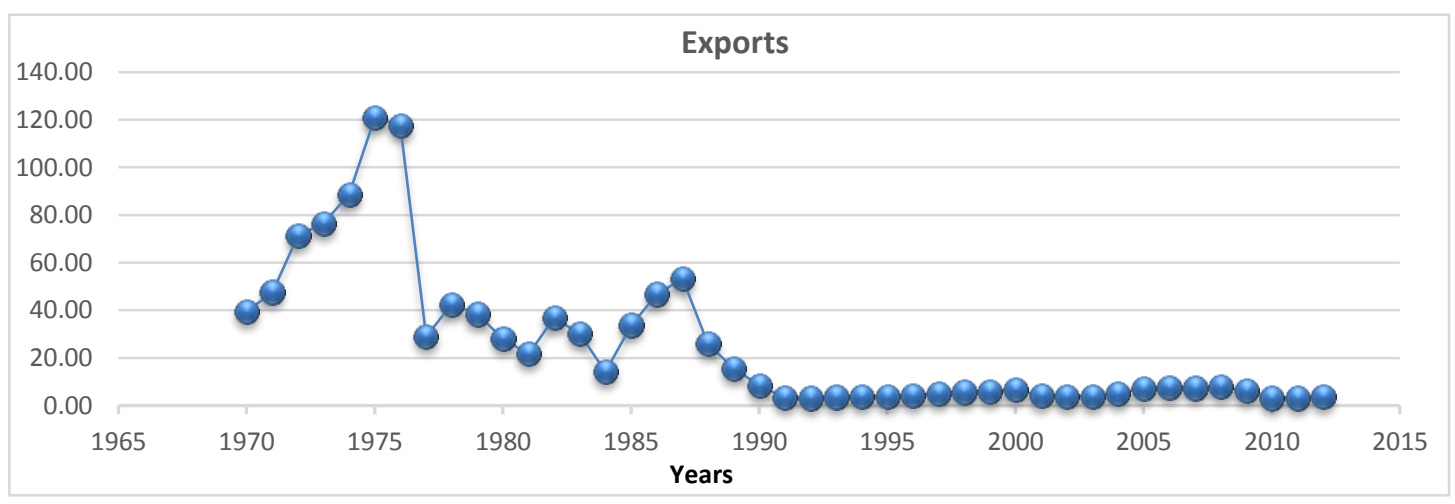

Figure 2. Exports 
The official development assistance that the country has received for development and growth as well as during times of need and cyclical droughts, such as in 1993, 2009 and 2011, is illustrated in Figure 3.

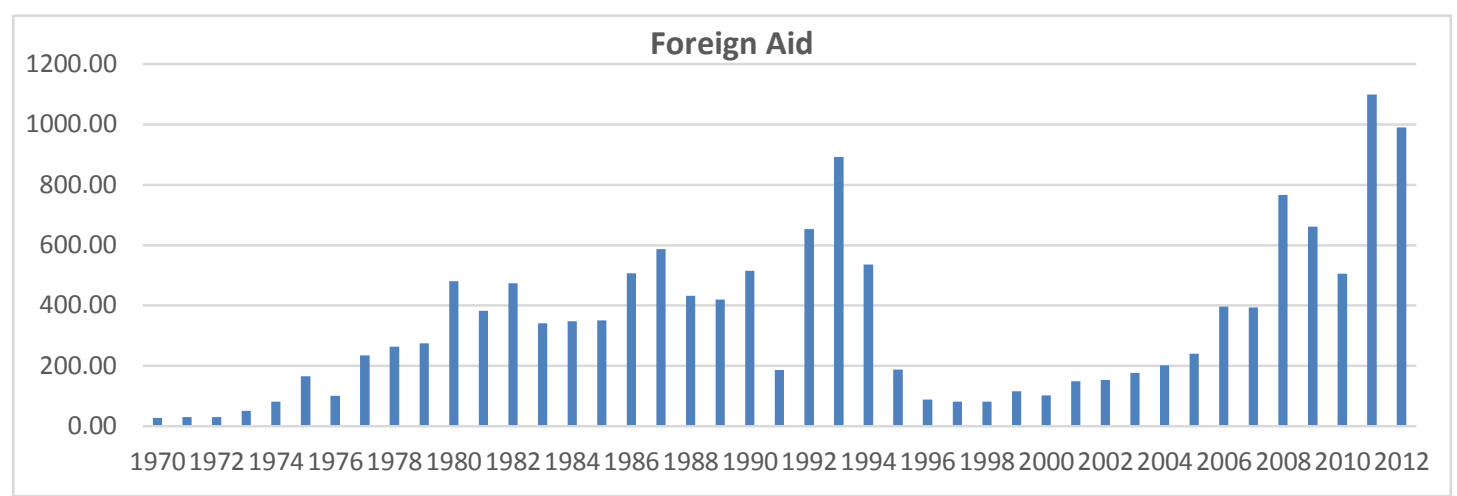

Figure 3. Foreign aid

Somalia owes external debt of approximately five billion dollars, and as shown in Figure 4, between 1980 and 2012, the rate of external debt increased radically as a matter of survival and to fund developmental projects that will in the long run contribute to GDP.

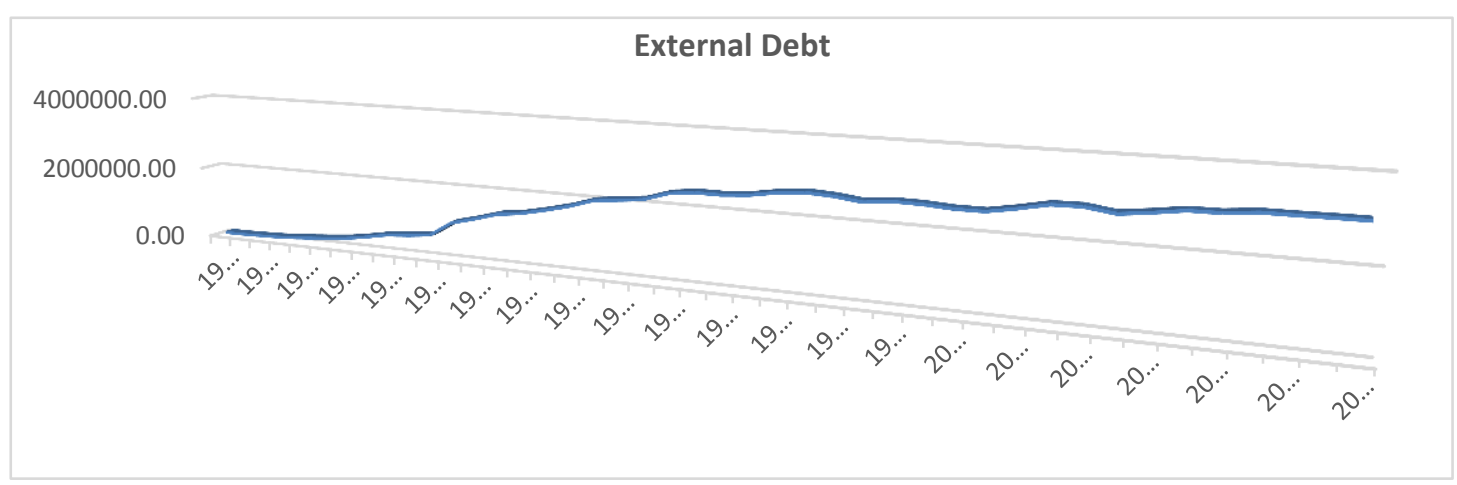

Figure 4. External debt

FDI is another indicator of economic growth; an increase in foreign investment will create employment and contribute to GDP. As shown in Figure 5, the decade corresponding to the relationship between the USA and Somalia initiated an increase in international investment; the establishment of Islamic courts in 2006 led to the reopening of the port of Mogadishu and the airport and increased security in the remainder of the country, thus attracting increased foreign investment in different sectors.

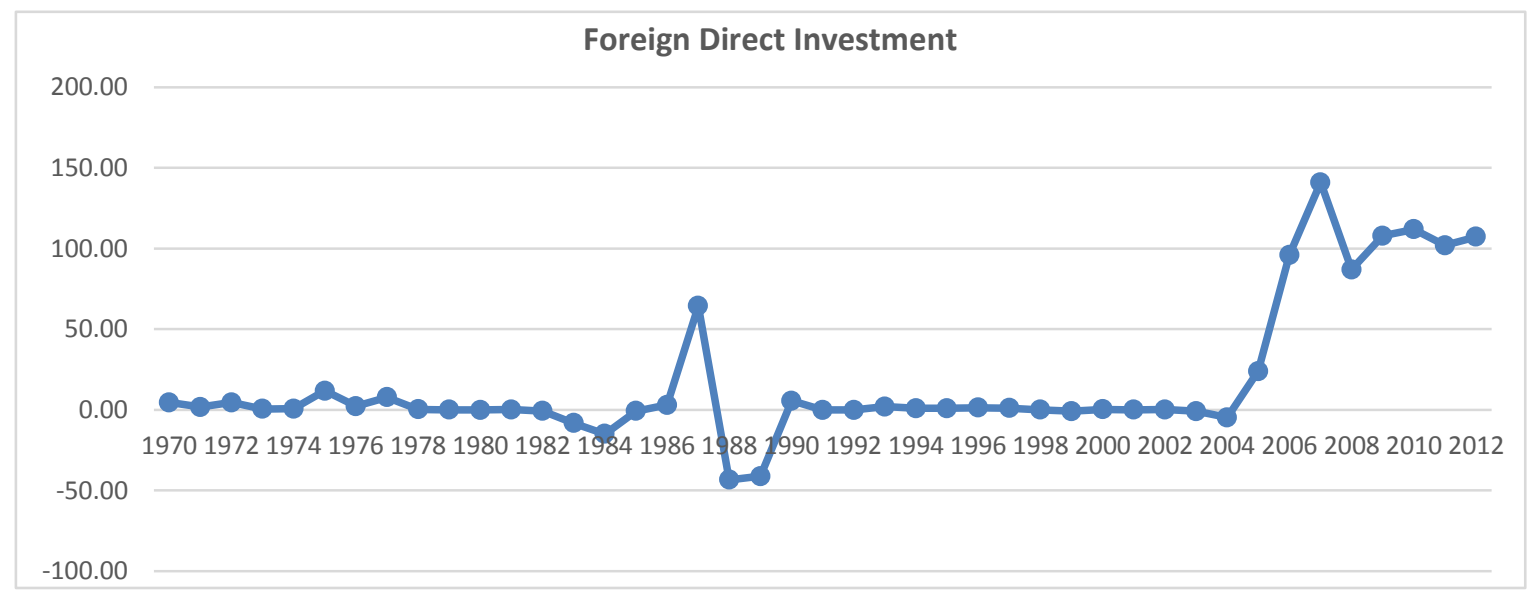

Figure 5. Foreign direct investment 
GCF comprises the production, transportation and distribution of that portion of a nation's output of goods and services that is not consumed immediately but is retained and added to the nation's stock of wealth. The greatest period of capital information in Somalia was 1985-1987. That period was followed by a decrease in capital formation, but in the last two decades, the country's capital has remained relatively constant (Figure 6).

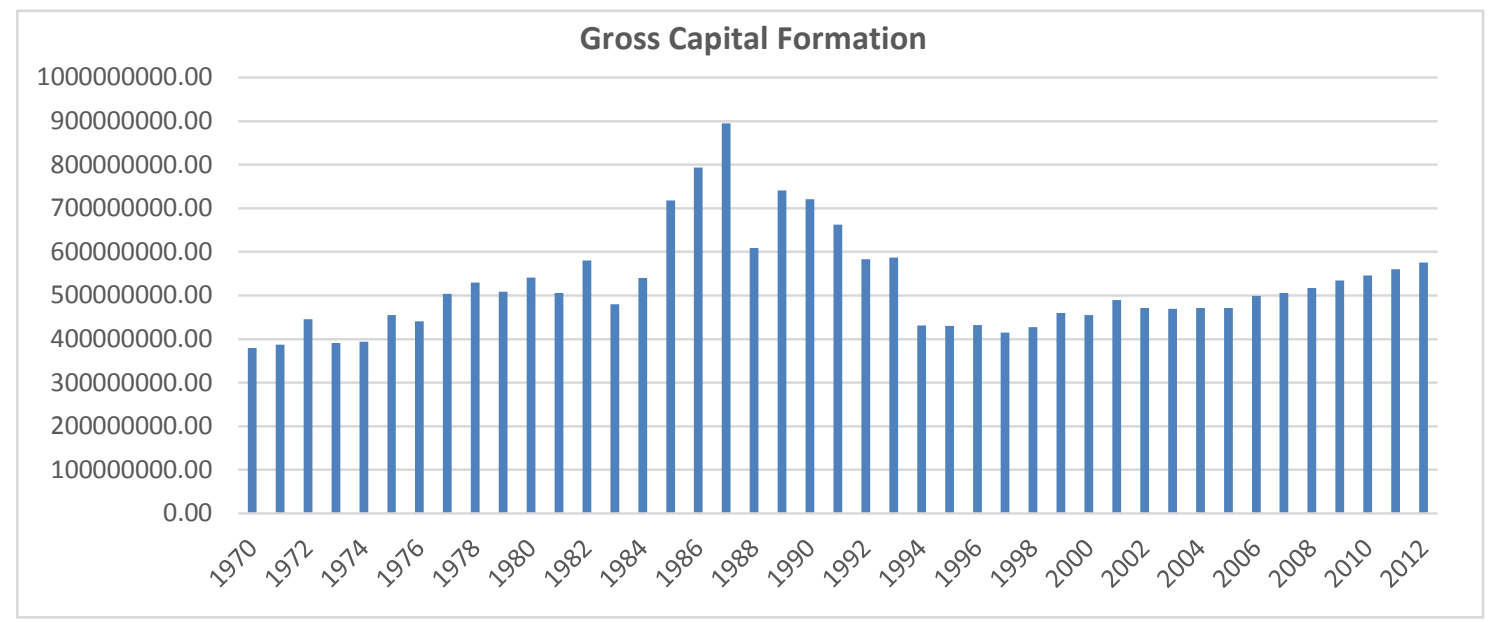

Figure 6. Gross capital formation

Governments generally experience greater expenditure due to national interest. During the study period, Somalia has experienced different periods of huge expenditures, leading to deficits (Figure 7). For example, in 1972-74, the country incurred increased expenditure due to the Dabadheer drought, which caused the deaths of many people and livestock in rural areas. In addition, in 1977-1980, the country was involved in a conflict with the neighboring country of Ethiopia, which required increased expenditure. Finally, between late 1986 and 1991 , the country experienced turmoil in its internal political system preceding the collapse of the state, which also caused excess expenditure.

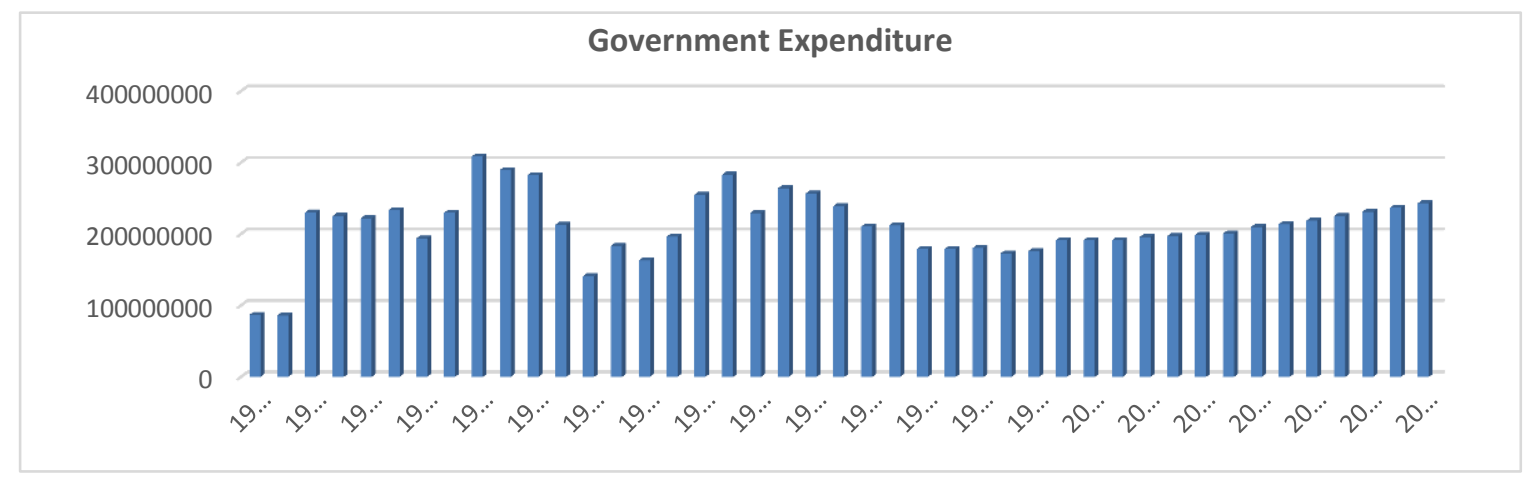

Figure 7. Government expenditure

GDP describes a country's economic growth and simply indicates overall growth in one graph. As shown in Figure 8, Somalia's economic growth was healthy in 1980-1990, with annual increases in GDP. After the collapse of the state, the country faced a massive decline in the growth rate, but between early 2001 and 2012 , a long-run recovery occurred. 


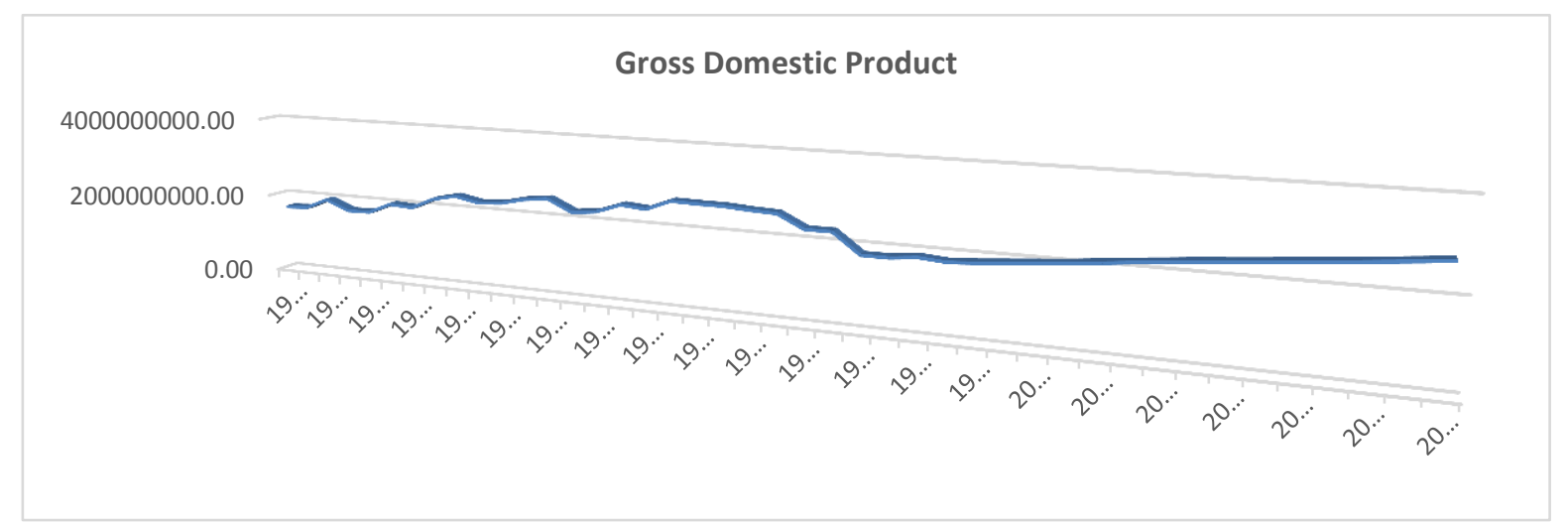

Figure 8. Gross domestic product

\subsection{Unit Root Test}

In the Augmented Dickey-Fuller (ADF) test and Phillips-Perron test, the variables GDP, FDI, ED, GCF, FA, GE and Export $\mathrm{X}$ do not have a unit root in the level model, indicating that these variables are not stationary either with a constant without a trend or with a constant with a trend because all absolute values of the t-statistics are greater than the critical value, which implies that we cannot reject the null hypothesis, $\mathrm{H}_{0}$. Therefore, the variables have a unit root, and $\mathrm{H}_{0}$ is accepted.

However, when the variables are converted to the first difference, all first-differenced variables, that is, D (GDP $(-1)$ ), and the remaining variables in the model become stationary, meaning that they do not have a unit root. Therefore, we shall use the first-differenced variables in our model because of their stationary nature.

Table 2. Unit root test

\begin{tabular}{|c|c|c|c|c|}
\hline \multirow[b]{2}{*}{ Variables } & \multicolumn{2}{|c|}{$\mathrm{ADF}$} & \multicolumn{2}{|c|}{$\mathrm{PP}$} \\
\hline & Constant without trend & Constant with trend & Constant without trend & Constant withtrend \\
\hline \multicolumn{5}{|l|}{ Level } \\
\hline GDP & -1.6747 & -1.7074 & -1.8667 & -1.9333 \\
\hline FDI & -1.5050 & -2.5090 & -1.5050 & -2.5090 \\
\hline ED & -2.1868 & 0.0896 & -1.8475 & -0.2671 \\
\hline GCF & -2.3638 & -2.3202 & -2.2556 & -2.2068 \\
\hline FA & -1.4332 & -2.0185 & -1.1576 & -1.9401 \\
\hline GE & -2.9297 & -3.5155 & -2.9297 & -5.5155 \\
\hline $\mathrm{X}$ & $-3.2354 * *$ & -2.0189 & -1.8407 & -3.0968 \\
\hline \multicolumn{5}{|c|}{$1^{\text {st }}$ Difference } \\
\hline$\Delta \mathrm{GDP}$ & $-6.6013 * * *$ & $-6.5149 * * *$ & $-6.6226 * * *$ & $-6.5474 * * *$ \\
\hline$\Delta$ FDI & $-7.7581 * * *$ & $-6.5783 * * *$ & $-8.6778 * * *$ & $-10.974 * * *$ \\
\hline$\Delta \mathrm{ED}$ & $-4.2033^{* * *}$ & $-4.7402 * * *$ & $-4.2033 * * *$ & $-4.6275^{* * *}$ \\
\hline$\Delta \mathrm{GCF}$ & $-8.2096^{* * *}$ & $-8.1270 * * *$ & $-8.2096^{* * *}$ & $-8.1270 * * *$ \\
\hline$\Delta \mathrm{FA}$ & $-7.6954 * * *$ & $-7.6705^{* * *}$ & $-7.8794 * * *$ & $-7.8716^{* * *}$ \\
\hline$\Delta \mathrm{GE}$ & $-2.9314 * * *$ & $-3.51809 * * *$ & $-2.9314 * * *$ & $-3.51809 * * *$ \\
\hline$\Delta \mathrm{X}$ & $-3.5440 * * *$ & $-7.8746^{* * * *}$ & $-6.6526^{* * *}$ & $-6.5537 * * *$ \\
\hline
\end{tabular}

\subsection{Regression Results}

Having validated the presence of a unit root in the first difference of each variable, we next examined the potential relationship between the dependent variable and independent variables using the OLD model. The relationships between economic variables, such as the explanatory factors in this study, and economic growth are generally inexact. Variables other than the determinants under investigation may affect economic growth. For example, inflation, exchange rates, interest rates, the difference between imports and exports and, more importantly, the savings and investment rates are likely to exert some influence over economic growth. Time-series data collected from the World Bank and IMF online databases were analyzed, and EViews software was used to interpret the parameters. 
Regression analysis was utilized to explore the relationships and the extent of impact of the determinants on economic growth in the context of Somalia. As shown in Table 3, multiple regression analysis of the determinants of economic growth yielded a coefficient of determination R2 of 0.786 . Thus, approximately $79 \%$ of the systematic variation in the endogenous (dependent) variable is explained by changes in the independent variables, indicating a good fit, and only $20.9 \%$ of the systematic variation in GDP is not explained by the model, which may be attributed to the error term or the residual. The Durbin Watson value of 1.124263 is greater than the R2 value of 0.7862 , implying that the overall model is significant and well fit at the $5 \%$ level of significance.

$\mathrm{ED}, \mathrm{FA}, \mathrm{GE}$, and $\mathrm{X}$ did not significantly predict the value of economic growth in Somalia. These four suggested explanatory factors were rejected in this model due to insignificance (Table 3).

Table 3. Estimation of model coefficients

\begin{tabular}{lllll}
\hline Variable & Coefficient & Std. Error & t-Statistic & Prob. \\
\hline ED & 0.022496 & 0.043976 & 0.511558 & 0.6122 \\
FA & 0.255916 & 0.043976 & -0.511558 & 0.077 \\
FDI & 1.553661 & .747103 & 2.079501 & 0.045 \\
GCF & 1.530317 & 0.294444 & 5.197312 & 0.000 \\
GE & 1.212803 & 0.657565 & 1.844384 & 0.0736 \\
X & -2.151959 & 1.447078 & -1.487106 & 0.1459 \\
C & 1.15 & 1.60 & 7.1612 & 0.0000 \\
\hline R Squared & & 0.786262 & Mean dependent variable & 2.21 \\
Adjusted R Squared & & 0.749621 & S.D. dependent variables & 3.12 \\
S.E. of regression & & 1.56 & Akaike info criterion & 40.71 \\
Sum squares resid & & 8.51 & Schwarz criterion & 41.008 \\
Log likelihood & & -848.099 & Hannan-Quinn criterion & $4 . .825$ \\
F-statistic & 21.4585 & Durbin Watson stat & 1.124263 \\
Prob (F-statistic) & & 0.000 & & \\
\hline
\end{tabular}

\subsection{Model Assumptions Test}

\subsubsection{Normality Test}

Normality tests are important to avoid affecting the results and obtaining biased conclusions. Before further analysis of the main variables in this study, such as FDI, ED, GCF, FA, X, and GE, and economic growth using GDP as the dependent variable, a normality test was conducted for the multivariate items. Several techniques for testing normality were employed, including histogram analysis and the Jarque-Bera test, which is a goodness-of-fit test of whether the skewness and kurtosis of the sample data match a normal distribution.

The sample size of this study is longer than forty years, increasing the likelihood that the data are normally distributed. The analysis of the frequencies revealed that the scores for skewness and kurtosis were below the suggested cut-off scores of 2 and 10, respectively. Moreover, as shown in Figure 2 below, histogram analysis indicated that the data were normally distributed. Thus, further analysis was performed using parametric tests.

The Jarque-Bera statistic was 0.082963 , and its corresponding p-value was .959 , which is higher than the significance level of 0.05 ; thus, we cannot reject the hull hypothesis, and the error terms are normally distributed.

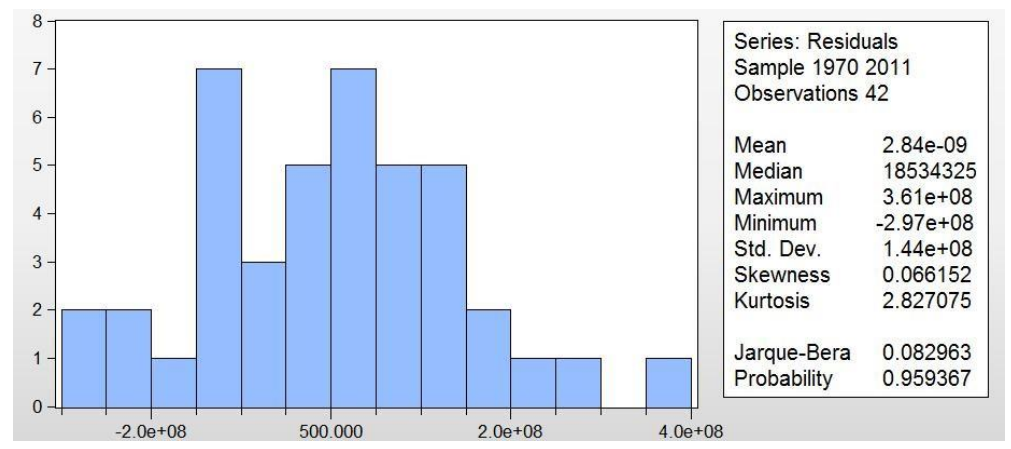

Figure 10. Normality test 


\subsubsection{Serial Correlation Test}

The assumptions of model fitting require an investigation of the relationship between a given variable and itself over various time intervals to evaluate the presence of serial correlation, which is frequently found in repeating patterns and indicates that the value of a variable affects its future value. To test serial correlation, we employed the Breusch-Godfrey test developed by Trevor S. Breusch and Leslie G. Godfrey.

The Breusch-Godfrey serial correlation LM test showed that the model was free from serial correlation, indicating that the error terms were not auto-correlated.

The obs R-squared was 8.9890, and its equivalent F-statistic was 4.4930, higher than the chosen significance level of $5 \%$. Thus, the null hypothesis cannot be rejected, and there is no serial correlation.

Table 4. Breusch-Godfrey serial correlation LM test

\begin{tabular}{llll}
\hline F-Statistic & 4.493049 & Prob. F $(2,33)$ & 0.0188 \\
Obs*R-squared & 8.989074 & Prob. Chi-Square (2) & 0.012 \\
\hline
\end{tabular}

\subsubsection{Heteroskedasticity}

Heteroskedasticity refers to differences in dispersion and occurs when the variability of a variable is unequal across the series of values of a second, predicting variable. The Breusch-Pagan-Godfrey test was employed to test the linear regression model for the presence of heteroskedasticity (Breusch and Pagan 1979). A good model is homoskedastic; i.e., the variance of the error terms of the model is constant.

As shown in Table 5, the obs R-squared (11.92769) and p-value (2.313696) were higher than the level of significance of $5 \%$. Thus, the null hypothesis was accepted, and the error terms were heteroskedastic.

Table 5. Heteroskedasticity test

\begin{tabular}{llll}
\hline F-Statistic & 2.313696 & Prob. F (6,35) & 0.0550 \\
Obs*R-squared & 11.92769 & Prob. Chi-Square (6) & 0.0636 \\
Scaled explained SS & 7.566937 & Prob. Chi-Square (6) & 0.2716 \\
\hline
\end{tabular}

\subsubsection{Multicollinearity Test}

Multicollinearity, which is also called collinearity, occurs when two or more independent variables are highly correlated, and thus one variable can be predicted from the other with a considerable degree of accuracy.

The correlation coefficient measure was used to assess the degree of the linear relationships among the five explanatory variables and identify highly correlated variables. As shown in Table 6, all variables were medium correlated, and thus there was no violation of the regression assumption.

Table 6 shows the result of the correlation analyses of the relationships among FDI, ED, GCF, FA, X, and GE. ED was positively correlated with FA ( $r=.48$ and $\mathrm{p}<0.01)$, FDI $(r=.46$ and $\mathrm{p}<0.01)$, GCF $(r=.23$ and $\mathrm{p}<0.01)$, GE $(\mathrm{r}=.071$ and $\mathrm{p}<0.01)$ and negatively correlated with $\mathrm{X}(\mathrm{r}=-.814$ and $\mathrm{p}<0.01)$. Positive relationships were also observed among other variables, but $\mathrm{X}$ was negatively correlated with all variables accept GE.

Table 6. Correlations between the explanatory variables

\begin{tabular}{lllllll}
\hline Variable & 1 & 2 & 3 & 4 & 5 & 6 \\
\hline External Debt & 1 & & & & & \\
Foreign Aid & 0.481 & 1 & & & & \\
Foreign Direct Investment & 0.465 & 0.615 & 1 & & & \\
Gross Capital Formulation & 0.235 & 0.515 & 0.125 & 1 & & \\
Government Expenditure & 0.071 & 0.406 & 0.225 & 0.542 & 1 & 1 \\
Export & -0.8140 & -0.364 & -0.247 & -0.122 & 0.062 & \\
\hline
\end{tabular}

\section{Discussion and Conclusion}

Regression analysis of the effects of FDI, ED, GCF, FA, X, and GE on the growth of the Somali economy in the period 1970-2012 was performed. The adjusted R-square of the model was 0.749621 or $75 \%$, indicated that the 
model fit the data well; the total variation in the observed behavior of GCF is jointly explained by the variation in GCF and FDI up to $75 \%$. The remaining $25 \%$ is accounted for by the stochastic error term.

To test the overall significance of the model, the F-statistic was used. To assess the individual statistical significance of the parameters, the t-statistics of the respective variables were considered. Based on their probability values, which were automatically generated during the computation process by the EViews software, only GCF and FDI were significant Thus, a major finding of this study is the presence of significant relationships between GCF and FDI and economic growth in Somalia.

The role of FDI in the growth process of any country has been a topic of intense debate. FDI is an important topic given its implications for poverty reduction in recipient countries with good economic institutions. No previous empirical studies of the impact of FDI and GCF on economic growth have been conducted in the Somali context. The present research analyzed the impact of determinants of economic growth in Somalia employing six different explanatory factors. Data for the years 1970-2012 were subjected to time-series analysis, and the OLS estimation method was used to estimate the parameters. The ADF and PP tests were employed as unit root tests. The literature provides evidence supporting positive impacts of the six determinants on economic growth. However, in the case of Somalia, only GCF and FDI are predicted to affect economic growth.

In conclusion, policy formulation, planning, budgeting, monitoring and service delivery are essential for economic development, and in fact, it is very difficult to obtain macroeconomic data due to the absence of efficient working political and economic institutions and the existing incapacity of macroeconomic data collection mechanisms. Thus, a reliable economic and non-economic data pool for the entire country is essential for facilitating the formulation and execution of a national development policy.

\section{References}

Ang, J. B., \& McKibbin, W. J. (2007). Financial liberalization, financial sector development and growth: Evidence from Malaysia. Journal of Development Economics, 84(1), 215-233. https://doi.org/10.1016/j.jdeveco.2006.11.006

Artelaris, P., Arvanitidis, P., \& Petrakos, G. (2007). Explaining knowledge-based economic dynamism in a global scale (No. DYNREG05).

Barro, R. J. (1991). Economic growth in a cross section of countries. The Quarterly Journal of Economics, 106(2), 407-443. https://doi.org/10.2307/2937943

Cheng, B. S., \& Lai, T. W. (1997). An investigation of co-integration and causality between energy consumption and economic activity in Taiwan. Energy Economics, 19(4), 435-444. https://doi.org/10.1016/S0140-9883(97)01023-2

Dritsakis, N., Varelas, E., \& Adamopoulos, A. (2006). The main determinants of economic growth: An empirical investigation with Granger causality analysis for Greece. European Research Studies Journal, 9(3-4), 47-58.

Faria, J. R., \& Carneiro, F. G. (2001). Does high inflation affect growth in the long and short run? Journal of Applied Economics, 4(1), 89-105.

Ghali, K. H. (1997). Government spending and economic growth in Saudi Arabia. Journal of Economic Development, 22(2), 165-172.

Hussain, S., \& Malik, S. (2011). Inflation and economic growth: Evidence from Pakistan. International Journal of Economics and Finance, 3(5), 262. https://doi.org/10.5539/ijef.v3n5p262

Liang, Q., \& Jian-Zhou, T. (2006). Financial development and economic growth: Evidence from China. China Economic Review, 17(4), 395-411. https://doi.org/10.1016/j.chieco.2005.09.003

Loizides, J., \& Vamvoukas, G. (2005). Government expenditure and economic growth: Evidence from trivariate causality testing. Journal of Applied Economics, 8(1), 125.

Lucas, R. E. (1988). On the mechanics of economic development. Journal of Monetary Economics, 22(1), 3-42. https://doi.org/10.1016/0304-3932(88)90168-7

Makki, S. S., \& Somwaru, A. (2004). Impact of foreign direct investment and trade on economic growth: Evidence from developing countries. American Journal of Agricultural Economics, 86(3), 795-801. https://doi.org/10.1111/j.0002-9092.2004.00627.x

Romer, P. M. (1986). Increasing returns and long-run growth. Journal of Political Economy, 94(5), 1002-1037. https://doi.org/10.1086/261420 
Saad, W. (2014). Financial development and economic growth: Evidence from Lebanon. International Journal of Economics and Finance, 6(8), 173. https://doi.org/10.5539/ijef.v6n8p173

Saqib, D., Masnoon, M., \& Rafique, N. (2013). Impact of foreign direct investment on economic growth of Pakistan.

Solow, R. M. (1956). A Contribution to the Theory of Economic Growth. The Quarterly Journal of Economics, 70(1), 65-94. https://doi.org/10.2307/1884513

Tyler, W. G. (1981). Growth and export expansion in developing countries: Some empirical evidence. Journal of Development Economics, 9(1), 121-130. https://doi.org/10.1016/0304-3878(81)90007-9

Worldbank. (2016). Retrieved May 12, 2017, from http://www.worldbank.org; http://www.worldbank.org/en/country/somalia/overview

\section{Copyrights}

Copyright for this article is retained by the author(s), with first publication rights granted to the journal.

This is an open-access article distributed under the terms and conditions of the Creative Commons Attribution license (http://creativecommons.org/licenses/by/4.0/). 